\title{
Epidemiological profile of brain tumors in Cameroon: a retrospective study
}

\author{
Mathieu Motah ${ }^{1,3}$, Daniel Gams Massi 1, $^{*} \mathbb{D}$, Fabien Fouda Bekolo ${ }^{1}$, Nkemontoh Akweseh Nju', \\ Aurélien Ndoumbe ${ }^{1}$, Mireille Moumi ${ }^{1,3}$, Anne Sango ${ }^{2}$, Paul Shu ${ }^{1}$ and Victor Eyenga ${ }^{5}$
}

\begin{abstract}
Background: Brain tumors represent group of neoplasms originating from intracranial tissues and the meninges. The aim of this study was to determine the epidemiological profile of brain tumors seen in a referral health center in Cameroon. We carried out a 10-year retrospective study in the neurosurgical, neurology, pathology, oncology and radiotherapy units of our hospital.

Results: We found 150 complete case files accounting for $0.7 \%$ of total admissions in the various units. Males accounted for $50.7 \%$ of the cases. Children less than 14 years represented $12.7 \%$ of cases $(n=19)$. Primary brain tumors constituted $92 \%(n=138)$. Most patients with primary brain tumors were between 25 and 54 years of age, making up $57 \%$ of cases $(n=79)$. The most prevalent histological type of brain tumor was meningioma $(26 \%, n=39)$, followed by astrocytoma (24.7\%, $n=37)$, and pituitary adenomas $(18 \%, n=27)$. The majority of cases presented with signs of raised intracranial pressure with headache being the most frequent symptom (88\%). Some patients presented with seizures (34\%), neurological deficit (13\%), visual disturbances (10\%), and cognitive disorders (7\%).
\end{abstract}

Conclusion: Young adults represent the most affected age group. Meningioma, astrocytoma and pituitary adenomas were the most frequent brain tumors in adults. Further studies are needed to assess the long-term outcome of patients with BTs.

Keywords: Epidemiology, Brain tumors, Meningioma, Astrocytoma, Pituitary adenoma, Cameroon

\section{Background}

Brain tumors (BT) refer to a mixed group of neoplasms originating from intracranial tissues $[1,2]$. There are two basic types of brain tumors: primary and metastatic brain tumors. Primary brain tumors originate and remain in the brain. Metastatic brain tumors originate from other organs in the body and spread to the brain. Primary BTs could equally be termed benign or malignant, depending on their ability to invade surrounding tissue. In 2015, the world annual incidence of primary BTs was estimated at 3.7 and 2.6 per 100,000 men and women, respectively, with a higher rate in developed $(5.1 / 100,000)$ than

\footnotetext{
*Correspondence: danny.gamsmassi@gmail.com

${ }^{2}$ Department of Internal Medicine and Paediatrics, Faculty of Health

Sciences, University of Buea, Buea, Cameroon

Full list of author information is available at the end of the article
}

developing countries (3.0/100,000) [3]. In African countries, little research has been conducted on the incidence of BTs. Davies in 1965 estimated central nervous system (CNS) tumors to represent $1.1 \%$ of all cancers registered in Uganda [4]. A higher incidence was reported in a hospital-based cancer registry from 2009 to 2010 in Nigeria, where brain cancer represented $3.9 \%$ of total cancers [5].

Clinical presentation of BTs ranges from headaches to more serious states like neurological deficits, seizures and blindness, depending on the characteristics of the tumor (histology, anatomical location) [6, 7]. Diagnosis of BTs has evolved over the years, from the use of gamma encephalography in the past to modern methods like CT scan, MRI, and brain biopsy [8]. The management is multidisciplinary, involving neurosurgeons, neurologists, oncologists, pathologists, radiologists, radiotherapists, and other health care providers depending on the 
characteristics of the tumor. Prognosis depends on the grade of the tumor [2]. In Cameroon, limited studies have been carried out on BTs. Eyenga et al. reported 231 cases of CNS tumors between 1996 and 2006 including $173(74.9 \%)$ BTs [9]. The estimated the annual BTs incidence in Cameroon from 2006 to 2010 was 8 per 100,000 with a male:female ratio of $1: 1.5$. The commonest histological types were astrocytomas, meningiomas, and ependymomas [10]. This study aimed to determine the epidemiological features of BTs in a referral health center in Cameroon.

\section{Methods}

\section{Study design}

This was a hospital-based retrospective study conducted in the oncology, neurosurgical, pathology, radiotherapy, intensive care and neurology units of a referral hospital in the economic capital of Cameroon. We carefully reviewed medical files of patients from January 2007 to December 2016. We included in this study, all patients admitted for the diagnosis of BT during the study period in our study site. Incomplete files were excluded.

This study was conducted with strict respect of ethical consideration, and was submitted and approved by the institutional ethical committee for research in human health of the University of Douala $\mathrm{N}^{\circ}$ CEIUDo/804/02/2017/T of the 13th of February 2017.

\section{Data collection}

After identifying the patients from the registers (hospitalization and outpatient registers), their files were retrieved from the hospital records department and examined individually. Data collection was done with the aid of structured forms designed for this study.

The diagnosis of BT was based on clinical and paraclinical evaluation. The patient's complete information was obtained from these files. Further data obtained from these case files included: the clinical presentation of each tumor type and means of diagnosis. We recorded in this study:

- Socio-demographic data: gender, age, and occupation.

- Patient history: comorbidities, and risk factors of BT.

- Clinical presentation: neurological and extra-neurological signs.

- Investigation results (brain CT scans, MRI, and biopsy).

\section{Statistical analysis}

Data were analyzed using SPSS 23.0. Categorical variables were presented as frequency $(n)$ and percentage (\%).
Table 1 General characteristics of the study population

\begin{tabular}{lcc}
\hline Variables & $\boldsymbol{n}$ & $\%$ \\
\hline Age (years) & & \\
$\leq 14$ & 19 & 12.7 \\
$15-24$ & 15 & 10.0 \\
$25-54$ & 82 & 54.7 \\
$\geq 55$ & 34 & 22.7 \\
Gender & & \\
Male & 76 & 50.7 \\
Female & 74 & 49.3 \\
Risk factors of brain tumors & & \\
Familial history of brain tumors & 4 & 2.7 \\
Working in synthetic manufacturing & 3 & 2.0 \\
HIV & 5 & 3.3 \\
Head trauma & 11 & 7.3 \\
Unidentified risk factor & 127 & 84.7 \\
\hline
\end{tabular}

Table 2 Prevalence of various histological types

\begin{tabular}{lll}
\hline Variables & $\boldsymbol{n}$ & $\%$ \\
\hline Meningioma & 39 & 26.6 \\
Astrocytoma & 37 & 24.7 \\
Pituitary adenoma & 27 & 18 \\
Metastasis & 12 & 8 \\
Hemangioblastoma & 9 & 6 \\
Medulloblastoma & 7 & 4.7 \\
Oligodendroma & 6 & 4 \\
Ependymoma & 3 & 2 \\
Pineoblastoma & 3 & 2 \\
Pineal carcinoma & 3 & 2 \\
Pineocytoma & 2 & 1.3 \\
Acoustic neuroma & 2 & 1.3 \\
\hline
\end{tabular}

Continuous variables were expressed as mean \pm standard deviation $(\mathrm{SD})$.

\section{Results}

A total of 200 patients were managed in this hospital for BTs. This accounts for about $1 \%$ of the total number of patients managed within the study period. Of these, 150 patients $(75 \%)$ had complete. There were 76 males $(50.70 \%)$. BTs were most common in age groups: $25-54$ years $(54.66 \%)$ and $>55$ years $(22.68 \%)$. Patients in whom no risk factor was identified accounted for $84.68 \%$ (Table 1).

The most common histological types found in our study were meningioma (26.60\%), astrocytoma (24.70\%), pituitary adenomas (18\%), and metastases (8\%) (Table 2). 
Meningioma was found to be most frequent (64\%) in patients within the ages of 25-54 years. There was a slight female predominance $(51.3 \%)$ as opposed to $48.7 \%$ in males. WHO grade I was the most common histological subtype. Astrocytoma was the most frequent tumor type in children between 0 and 14 years of age. WHO grade IV tumors were the most common subtypes. Pituitary adenomas commonly affected females. Lung and breast cancers were the most frequent sources of brain metastases (Table 3).
Frequent clinical manifestations included: headaches (88\%), blurred vision (58\%), vertigo (38.7), and seizures (34). Details on clinical manifestation are found in Fig. 1.

\section{Discussion}

Prevalence and socio-demographic characteristics

The aim of this study was to determine the epidemiological profile of BTs in a referral hospital in Cameroon. A total of 150 cases were recorded during this period giving an annual frequency of 15 cases per year. In Nigeria,

Table 3 characteristics of the commonest BTs

\begin{tabular}{|c|c|c|c|c|c|c|}
\hline Variables & Meningioma $n(\%)$ & Astrocytoma $n$ (\%) & & $\begin{array}{l}\text { Pituitary } \\
\text { adenomas } n \\
\text { (\%) }\end{array}$ & & Metastasis $n(\%)$ \\
\hline \multicolumn{7}{|l|}{ Age range } \\
\hline $0-14$ & $2(5.13)$ & $8(20.51)$ & & - & & - \\
\hline $15-24$ & - & $5(13.51)$ & & $5(18.52)$ & & $1(8.33)$ \\
\hline $25-54$ & $25(64.1)$ & $19(48.72)$ & & $18(66.67)$ & & $3(25)$ \\
\hline$\geq 55$ & $12(30.77)$ & $5(13.51)$ & & $4(14.81)$ & & $8(66.67)$ \\
\hline \multicolumn{7}{|l|}{ Gender } \\
\hline Male & $19(48.72)$ & $20(54.05)$ & & $11(40.74)$ & & $6(50)$ \\
\hline Female & $20(52.63)$ & $17(45.95)$ & & $16(59.26)$ & & $6(50)$ \\
\hline \multicolumn{7}{|c|}{ Histological subtypes } \\
\hline WHO Grade I & $25(64.1)$ & $11(29.73)$ & Prolactinoma & $15(55.50)$ & Lung cancer & $6(50)$ \\
\hline WHO Grade II & $6(15.38)$ & $3(8.11)$ & Cushing's disease & $5(18.6)$ & Breast cancer & $4(33.33)$ \\
\hline WHO Grade III & $8(20.51)$ & $2(5.41)$ & Acromegaly & $4(14.8)$ & Hodgkin's lymphoma & $1(8.33)$ \\
\hline WHO Grade IV & - & $21(56.76)$ & TSH adenoma & $3(11.1)$ & Burkitt's lymphoma & $1(8.33)$ \\
\hline
\end{tabular}

\section{Cognitive disorders}

Visual disturbances

Motor deficit

Vomiting
Seizures
Vertigo

Blurred vision

Headaches
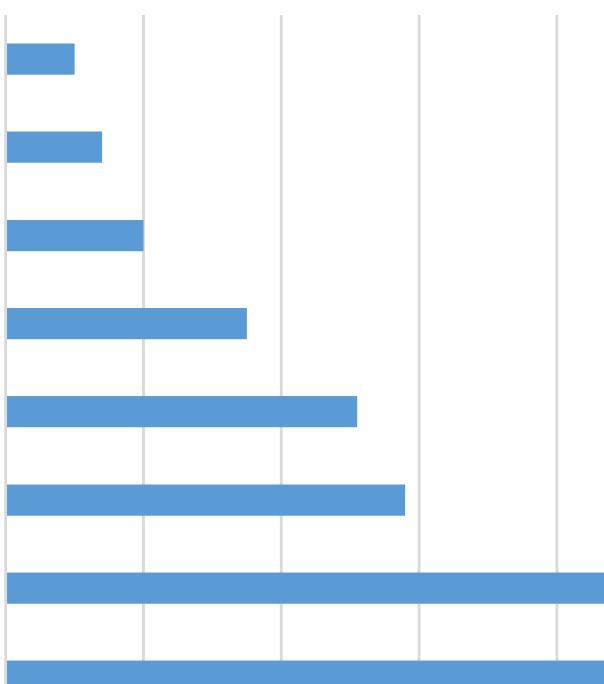

0

40

60

80

100

120

Fig. 1 Common clinical manifestations 
Olasode et al. reported 210 cases of intracranial neoplasms (annual incidence of 21 cases per year) in a retrospective study carried out over 11 years at the University College Hospital of Ibadan [5]. Eyenga et al. reported a frequency of $6.3 \%$ [9]. This annual frequency does not necessarily reflect the reality. If this hospital is the main referral hospital, other health facilities in Douala (Cameroon) provide neuro-oncological care of patients. Moreover, some of the patients may not come to this hospital because of limited financial resources.

This study found a slight male predominance. Soyemi et al. [11] reported a similar finding in a tertiary health facility in Nigeria. However, this differs from what Enow Orock et al. [10] obtained from the cancer registry in Yaoundé and pathological unit of Buea Regional Hospital. They reported a female predominance $62.5 \%$. Literature reports a slight male predominance [10].

Most of patients in this study were young adults (2454 years). Olasode et al. observed that the peak age group for intracranial tumors in adults was 25-30 years and Soyemi et al. had similar findings (21-30 years) [5, 11]. All of these findings are quite similar to our results. This age group represents the active population of our study area.

\section{Histological types of brain tumors}

Primary BTs were the most common types in our patients. Olasode et al. found similar results with primary tumors making up $77 \%$ of the cases and metastases $23 \%$ of intracranial neoplasms [5].

Meningiomas were found to be most frequent in patients within the ages of $25-54$ years. WHO grade I were the most common histological subtype in our series. Eyenga et al. and Mwangombe et al. [9, 12] found similar findings. Other studies reported astrocytomas to be more frequent $[10,13]$. The slight female predominance among cases of meningioma is similar to the results of Mwangombe et al. in Kenya [12].

Gliomas accounted for about one-third of cases in this study. This is very similar to the $33 \%$ reported by Olasode et al. in 2000 [5]. Astrocytomas were the most common type, followed by oligodendromas, and ependymomas. More than half of astrocytomas were grade IV. Similarly, Mwangombe et al. [12] reported 22 cases of glioblastomas (55\%) in 2006. Andrews et al. found high-grade astrocytoma to be the most common intracranial neoplasm in their study (23\%) [13]. Literature reports that astrocytomas make up $50 \%$ of brain tumors and glioblastomas are the most frequent form of astrocytoma $[5,12$, 13]. Oligodendromas are far less frequent than astrocytomas in this study. Very similar findings were reported by some authors $[5,14]$.
Ependymomas represented $2 \%$ of all intracranial neoplasms in this study which is comparable to the $1.1 \%$ in a Caucasian series [15]. In USA, ependymoma is more common in children than adults [16]. We found ependymoma only in adults. Medulloblastoma is the commonest intracranial neoplasm in American children [17]. In the present study, it was the second most common neoplasm after astrocytoma. Three adult cases of medulloblastoma were recorded, which is similar to the reports in USA [7].

Pituitary adenomas were the third most common type in this series. This is comparable to the $17.8 \%$ obtained by Cushing et al. [15]. Lower frequency of pituitary adenomas (9.86\%) has been observed by Mwangombe et al. [12]. Tumors of the pineal region accounted for 5.3\% namely pineoblastomas, pineal carcinomas, and pineocytomas. A study done in Japan indicates that these tumors represent 3.5\% of intracranial tumors [18]. Acoustic neuromas were one of the least frequent tumor types in our population. With only two cases found, the annual incidence is far less than the 1 to 20 per 100,000 reported by Edward et al. in 2006 [19].

About two-thirds of brain metastases were above 55 years; no case of brain metastases was reported by Soyemi et al. in Nigeria [11]. Half of brain metastasis originated from lung cancers. One-third of cases were breast cancers. These results differ from the report of Olasode et al. [5] who found choriocarcinomas as main source of metastases followed by Burkitt's lymphoma. This difference may be related to the increasing trends in incidence and prevalence of lung and breast cancers over the years $[20,21]$.

Burkitt's lymphoma is mainly a pediatric tumor and this study does not show pediatric involvement in brain metastases [22].

\section{Clinical manifestations}

Commonest clinical features were signs of raised ICP including: headache, blurred vision, vertigo and vomiting. These signs can be associated with mass effect on the brain by tumor. Other signs included seizures, motor deficits, and cognitive deficits. These could be attributed to direct effect on critical brain areas by the tumor, mass effect, leptomeningeal spread and compromise of vascular flow to these areas [23]. These proportions agree with literature reports which indicate signs of raised intracranial pressure as most common clinical presentations of brain tumors $[2,9,10,15,24]$.

\section{Conclusion}

BTs are serious conditions with an annual incidence of 15 cases per year. Young adults are mainly affected with a slight male predominance. Primary BTs represent the 
majority of cases leading by meningiomas in adults, and astrocytoma in children. Metastases were mainly found in older patients, leading by lung and breast cancers. Signs of raised ICP were recorded as the most common clinical presentations. Further studies are needed to determine the population-based prevalence in our community.

\section{Abbreviations}

BT: Brain tumor; CNS: Central nervous system; CT: Computed tomography; HIV: Human immunodeficiency virus; ICP: Intracranial pressure; MRI: Magnetic resonance imaging; SD: Standard deviation; SPSS: Statistical Package for Social Sciences; USA: United States of America; WHO: World Health Organization.

\section{Acknowledgements}

To the staff of the different units involved in the data collection.

\section{Authors' contributions}

MM: conception, design, writing, and review; DGM: conception, design, analysis, writing, and review; FFB: conception, design, and review; NAN: conception, data collection, and review; AN, MM, AS, PS: draft and review; VE: conception, draft and review. All authors read and approved the final manuscript.

\section{Funding}

This study was funded by the authors.

\section{Availability of data and materials}

The datasets used and/or analyzed during the current study are available from the corresponding author on reasonable request.

\section{Declarations}

\section{Ethics approval and consent to participate}

This study was conducted with strict respect to ethical consideration, and was submitted and approved by the institutional ethical committee for research in human health of the University of Douala N ${ }^{\circ}$ CEI-UDo/804/02/2017/T of the 13th of February 2017.

\section{Consent for publication}

Not applicable.

\section{Competing interests}

The authors declare that they have no competing interests.

\section{Author details}

${ }^{1}$ Department of Surgery, Faculty of Medicine and Pharmaceutical Sciences, University of Douala, Douala, Cameroon. ${ }^{2}$ Department of Internal Medicine and Paediatrics, Faculty of Health Sciences, University of Buea, Buea, Cameroon. ${ }^{3}$ Neurosurgical Unit, Douala General, Douala, Cameroon. ${ }^{4}$ Nerosurgical Unit, Douala General Hospital, Douala, Cameroon. ${ }^{5}$ Faculty of Medicine and Biomedical Sciences, University of Yaoundé I, Yaoundé, Cameroon.

Received: 12 June 2021 Accepted: 2 September 2021

Published online: 17 September 2021

\section{References}

1. Black KL, Mazziotta JC, Becker DP. Brain tumors. West J Med. 1991;154(2):186-97.

2. McKinney PA. Brain tumours: incidence, survival, and aetiology. J Neurol Neurosurg Psychiatry. 2004;75(suppl 2):ii12-7.

3. Ostrom QT, Gittleman H, Xu J, Kromer C, Wolinsky Y, Kruchko C, et al. CBTRUS statistical report: primary brain and other central nervous system tumors diagnosed in the United States in 2009-2013. Neuro Oncol. 2016;18:v1-75. https://doi.org/10.1093/neuonc/now207.
4. Davies JN, Knowelden J, Wilson BA. Incidence rates of cancer in Kyandondo County, Uganda, 1954-1960. J Natl Cancer Inst. 1965;35(5):789-821.

5. Olasode BJ, Shokunbi MT, Aghadiuno PU. Intracranial neoplasms in Ibadan Nigeria. East Afr Med J. 2000;77:4-8. https://doi.org/10.4314/eamj. v77i1.46360.

6. Goel A. Tumour induced hydrocephalus and oedema: pathology or natural defence. J Postgrad Med. 2002;48(2):153.

7. Siegel A, Sapru HN. Essential neuroscience. Philadelphia: Lippincott Williams \& Wilkins; 2010. p. 380

8. Surawicz TS, McCarthy BJ, Kupelian V, Jukich PJ, Bruner JM, Davis FG. Descriptive epidemiology of primary brain and CNS tumors: results from the Central Brain Tumor Registry of the United States, 1990-1994. Neuro Oncol. 1999:1:14-25.

9. Eyenga V-C, Ngah JE, Atangana R, Etom E, Ngowe MN, Bassong Y, et al. Les tumeurs du systeme nerveux central aux Cameroun: histopathologie, demographie. Cah Détudes Rech Francoph Santé. 2008;18(1):39-42.

10. Enow-Orock G, Enoh Nkongho K, Verla V, et al. Brain tumors: clinicopathological aspects of 40 cases in Cameroon and the review of literature. AJIH. 2015:5(01):18-23.

11. Soyemi SS, Oyewole OO. Spectrum of intracranial tumours in a tertiary health care facility: our findings. Pan Afr Med J. 2015;20:24. https://doi. org/10.11604/pamj.2015.20.24.4935.

12. Mwangombe NJ, Ombachi RB. Brain tumours at the Kenyatta National hospital, Nairobi. East Afr Med J. 2006;77(8):444-7.

13. Andrews NB, Ramesh R, Odjidja T. A preliminary survey of central nervous system tumors in tema Ghana. West Afr J Med. 2003:22(2):167-91.

14. Jackson JG, Okubadejo DA. A review of intracranial tumours seen in necropsies at the University College Hospital, Ibadan between 1957 and 1961. West Afr Med J. 1963;12:251-63.

15. Cushing $\mathrm{H}$. Intracranial tumours. Notes upon a series of two thousand verified cases with surgical mortality, percentages pertaining thereto. Sprinfield: Charles C. Thomas; 1932. p. 1-50.

16. Schoenberg BS, Schoenberg DG, Christine BW, et al. The epidemiology of primary intracranial neoplasms of childhood: a population study. Mayo Clin Proc. 1976;51:51-6.

17. Loda M, Mucci L, Mittelstadt ML, Hemelrijck MV, Cotter MB. Pathology and epidemiology of cancer. Berlin: Springer; 2016. p. 664.

18. Sayegh ET, Aranda D, Kim JM, Oh T, Parsa AT, Oh MC. Prognosis by tumor location in adults with intracranial ependymomas. J Clin Neurosci. 2014;21(12):2096-101.

19. Edwards CG, Schwartzbaum JA, Lönn S, Ahlbom A, Feychting M. Exposure to loud noise and risk of acoustic neuroma. Am J Epidemiol. 2006;163(4):327-33. https://doi.org/10.1093/aje/kwj044. Erratum in: Am J Epidemiol. 2006;163(12):1163. (Epub 2005 Dec 15).

20. Lam WK, White NW, Chan-Yeung MM. Lung cancer epidemiology and risk factors in Asia and Africa. Int J Tuberc Lung Dis. 2004;8(9):1045-57.

21. Joko-Fru WY, Jedy-Agba E, Korir A, Ogunbiyi O, Dzamalala CP, Chokunonga $E$, et al. The evolving epidemic of breast cancer in sub-Saharan Africa: results from the African Cancer Registry Network. Int J Cancer. 2020;147:2131-41. https://doi.org/10.1002/ijc.33014.

22. Miron I, Miron L, Lupu WV, Ignat A. Silent presentation of multiple metastasis Burkitt lymphoma in a child: a case report and review of the literature. Medicine (Baltimore). 2017;96(28):e7518. https://doi.org/10. 1097/MD.0000000000007518.

23. Abolanle KAA, Amina S, Muhammad A, Hina A, Omowumi KT, et al. Brain tumor: an overview of the basic clinical manifestations and treatment. Glob J Cancer Ther. 2020;6(1):038-41. https://doi.org/10.17352/25815407.000034

24. Stagno V, Mugamba J, Ssenyonga P, Kaaya BN, Warf BC. Presentation, pathology, and treatment outcome of brain tumors in 172 consecutive children at CURE Children's Hospital of Uganda. The predominance of the visible diagnosis and the uncertainties of epidemiology in sub-Saharan Africa. Childs Nerv Syst. 2014;30(1):137-46.

\section{Publisher's Note}

Springer Nature remains neutral with regard to jurisdictional claims in published maps and institutional affiliations. 